\title{
O bibliotecário na editoração de periódicos científicos eletrônicos: possibilidades empreendedoras
}

\author{
Jorge Santa Anna ${ }^{1}$
}

\section{Resumo}

Promove reflexões acerca de novas formas de atuação do bibliotecário, sobretudo, na editoração eletrônica de periódicos científicos. Objetiva apresentar atividades desempenhadas por bibliotecário nesse segmento, de modo a confirmar as possibilidades empreendedoras advindas desse contexto de trabalho. O método adotado caracteriza o estudo como descritivo, de abordagem qualitativa, com procedimentos de pesquisa bibliográfica e relato de experiência, a partir da vivência prática de um bibliotecário integrante da equipe editorial de um periódico científico. Constatou- se que esse profissional auxilia nas atividades de gestão do periódico, melhorando a interface da revista e atribuindo papéis aos membros da equipe, como também desempenha, de forma exclusiva, as atividades de revisão textual e normalização; tratamento e organização de metadados; diagramação e, por fim, publicação de nova edição. Além dessas atividades, outras mais complexas se fazem necessárias, como a manutenção do sistema de gerenciamento e elaboração de estratégias que melhorem o armazenamento da produção científica e acarrete melhorias no sistema de recuperação da informação. Em suma, espera-se que essas constatações despertem possibilidades empreendedoras nos bibliotecários do século XXI.

Palavras-chave: Periódicos científicos; Editoração eletrônica; Prestação de serviços bibliotecários; Bibliotecário empreendedor.

\section{El bibliotecario en la edición de periódicos científicos electrónicos: posibilidades emprendedoras}

\section{Resumen}

Este artículo promueve reflexiones acerca de nuevas formas de actuación del bibliotecario, sobre todo en la publicación electrónica de periódicos científicos. El objetivo es presentar actividades realizadas por los bibliotecarios en ese segmento, para confirmar las posibilidades emprendedoras derivadas de ese contexto de trabajo. El método adoptado caracteriza el estudio como descriptivo, de abordaje cualitativo, con procedimientos de investigación bibliográfica y relato de experiencia, a partir de la vivencia práctica de un bibliotecario integrante del equipo editorial de un periódico científico. Se constató que ese profesional auxilia

\footnotetext{
${ }^{1}$ Doutorando do Programa de Pós-Graduação em Gestão e Organização do Conhecimento da Universidade Federal de Minas Gerais (UFMG), campus da Pampulha, Belo Horizonte (Brasil). Correo electrónico: jorjao20@yahoo.com.br
} 
en las actividades de gestión del periódico, mejorando la interfaz de la revista y asignando papeles a los miembros del equipo, como también desempeña, de forma exclusiva, las actividades de revisión textual y normalización; tratamiento y organización de metadatos; y, por último, publicación de nueva edición. Además de esas actividades, otras más complejas se hacen necesarias, como el mantenimiento del sistema de gestión y elaboración de estrategias que mejoren el almacenamiento de la producción científica y acarrean mejoras en el sistema de recuperación de la información. En suma, se espera que esas constataciones despierten posibilidades emprendedoras en los bibliotecarios del siglo XXI.

Palabras clave: Periódicos científicos; Edición electrónica; Prestación de servicios bibliotecários; Bibliotecario emprendedor.

\title{
The librarian in the editoring of electronic scientific newspapers: entrepreneurial possibilities
}

\begin{abstract}
It promotes reflections about new ways of the librarian, especially in the electronic publishing of scientific journals. It aims to present activities performed by librarians in this segment, in order to confirm the entrepreneurial possibilities arising from this work context. The adopted method characterizes the study as descriptive, with a qualitative approach, with bibliographic research procedures and experience reports, based on the practical experience of a librarian who is part of the editorial team of a scientific journal. It was verified that this professional assists in the activities of managing the journal, improving the interface of the journal and assigning roles to team members, as well as performing exclusively the activities of textual review and standardization; treatment and organization of metadata; layout and, finally, publication of a new edition. In addition to these activities, other more complex ones are necessary, such as the maintenance of the management system and the elaboration of strategies that improve the storage of scientific production and bring about improvements in the information retrieval system. In sum, these findings are expected to spark entrepreneurial possibilities in 21 st century librarians.
\end{abstract}

Keywords: Scientific journals; Electronic publishing; Provision of library services; Entrepreneurial librarian.

\section{Introdução}

O mercado editorial de publicações tem demandado o aparecimento de diversas atividades de trabalho, por conseguinte, inúmeros cargos, funções e até profissionais especializados são requeridos para garantir a efetiva comunicação e divulgação das informações publicadas em diversos recursos 
ou fontes de informação registrada, tais como livros, periódicos, bases de dado, sejam eles nos formatos impressos quanto eletrônicos.

Com efeito, o trabalho editorial tem se apresentado como um segmento potencial de empregabilidade em diversas profissões, desde aquelas ligadas ao desenvolvimento e estruturação das fontes de informação, até aquelas envolvidas com a disseminação dessas fontes na sociedade. Trata-se de um campo de trabalho originado em nossos primórdios e que vem se redefinindo ao longo dos tempos.

Historicamente, ainda no período antigo das civilizações, manifestavam-se os trabalhadores responsáveis pela comercialização de manuscritos, os livreiros, os quais realizavam suas atividades em feiras livres (Knapp, 1992). No entanto, nessa época, em virtude da forte censura, as atividades eram realizadas informalmente, sendo que esse quadro histórico transformou-se radicalmente, a partir da invenção da impressa, no século $\mathrm{XV}$, e a partir do processo de democratização do conhecimento, evidenciado nos séculos seguintes, como apontou Burke (2003).

Além desses importantes acontecimentos históricos que contribuíram para o crescimento do mercado editorial, pode-se citar, também, o nascimento dos periódicos científicos, a partir do século XVII. Os periódicos científicos são considerados como um dos principais fatores que viabilizaram a explosão documental vivenciada no século $\mathrm{XX}$ e, sua migração para o suporte eletrônico acarretou, ainda mais, o crescimento das publicações que divulgam os achados de pesquisa (Rodrigues \& Marinho, 2009).

Portanto, a reconfiguração do mercado editorial consolida-se, de forma intensa, com o surgimento do processo de editoração eletrônica, o qual, a cada dia, redefine as atividades de comunicação, os recursos e ferramentas utilizados nessas atividades e, principalmente, o papel desempenhado pelos profissionais que atuam nesse mercado.

Dentre os diversos profissionais atuantes nesse mercado, destaca-se, sobremaneira, o bibliotecário, o qual possui competências e habilidades para identificação, tratamento, organização, recuperação e disseminação das diversas fontes de informação registrada. Logo, nos dias de hoje, observa-se a ampliação das práticas bibliotecárias realizadas no âmago dos periódicos científicos eletrônicos, segmento de mercado que viabiliza possibilidades empreendedoras para esse e outros profissionais, as quais são demandadas para garantir efetividade no fluxo da comunicação científica no ambiente digital.

Nesse contexto, há de se concordar que, com a editoração eletrônica, “[...] simplifica-se o processo, especializam-se as atividades e configuram-se novas possibilidades de atuação para o bibliotecário, especialmente no que tange à gestão e normalização de periódicos científicos [...]” (Maiome \& Tálamo, 2008, p. 301, grifo nosso).

Embora a atuação em periódicos científicos venha se fortalecendo, sendo 
muito discutida na literatura, é possível identificar um nicho de mercado para o bibliotecário, ainda pouco explorado. Todavia, sustentamos nossos argumentos na tese de que, esse profissional, no atual século, pode desenvolver habilidades empreendedoras, independente do ramo de atuação ou segmento de mercado que queira intervir e atuar, tendo em vista atender necessidades específicas do público-alvo. Assim, o bibliotecário é um trabalhador capaz de "[...] identificar e dirigir necessidades, e que pode implementar, vender, e avaliar iniciativas" (Mathews, 2007, p. 1).

Por decorrência dessas reflexões, apresenta-se este estudo preliminar, cujo objetivo é apresentar atividades desempenhadas por bibliotecário no processo de editoração de periódicos eletrônicos, de modo a confirmar as possibilidades empreendedoras advindas desse contexto de trabalho.

Para se atingir tal objetivo, têm-se os seguintes procedimentos intermediários, que são: 1 - contextualizar o trabalho bibliotecário no âmago dos periódicos científicos e, 2 - identificar possibilidades de atuação empreendedora, haja vista as dificuldades e instabilidades enfrentadas com o uso das plataformas digitais dos periódicos.

Os procedimentos metodológicos utilizados para alcance desses objetivos foram a pesquisa bibliográfica e relato de experiência, a partir da vivência prática de um bibliotecário integrante da equipe editorial de um periódico científico. Portanto, o artigo que ora se apresenta constitui um recorte de uma pesquisa mais aprofundada sobre atuação do bibliotecário no mercado editorial de periódicos, sendo caracterizado, neste texto, como um estudo descritivo, de abordagem qualitativa.

\section{Trabalho bibliotecário em periódicos científicos: breves fundamentos teóricos}

A sociedade da informação desencadeou inúmeros reflexos nas práticas sociais e profissionais, uma vez que o recurso que sustenta as atividades de um dado contexto é a informação. $\mathrm{O}$ avanço tecnológico foi fundamental para promover a explosão do número de publicações, nos mais diferenciados formatos e estilos, fato esse que impacta diretamente na forma de atuação dos profissionais que lidam com o recurso informação (McGarry, 1999).

Dentre esses profissionais, destaca-se o bibliotecário, que, segundo Valentim (2000), esse profissional, em meio à explosão informacional, tem a possibilidade de vincular-se a diferentes organizações, além de prestar serviços que proporcionem o tratamento e disponibilização adequada da informação, acarretando contribuições nas tomadas de decisão e qualificando processos e atividades.

As demandas por serviços de informação de qualidade têm estimulado o crescimento dos campos de atuação de bibliotecários e profissionais da informação. Em linhas gerais, além de atividades tradicionais, como formação e gestão de acervos, cresce a procura por profissionais 
especializados para atuar na consultoria (Santa Anna \& Pereira, 2014), na editoração de livros (Souza, 2017) e periódicos (Santos, 2016), dentre outras atividades, o que desperta a consolidação do empreendedorismo bibliotecário na sociedade informatizada (Santa Anna, Silva \& Costa, 2018).

O empreendedorismo bibliotecário é um tema emergente no século XXI e representa um campo potencial para o bibliotecário e de grande valor para a sociedade. Empreender na Biblioteconomia é o mesmo que inovar no segmento corporativo, em que os profissionais têm a oportunidade de ampliar seus fazeres, de modo que '[...] possam se 'reinventar', enfrentando os desafios da sociedade contemporânea, e se adequando às novas tendências, garantindo para a ascensão da área no decorrer das próximas décadas" (Santa Anna, Silva \& Costa, 2018, p. 290).

Dentre os vários nichos de mercado para o bibliotecário empreendedor, destacam-se as atividades prestadas na editoração, como descrito no estudo de Santos (2016) e Souza (2017). Essas atividades demandam de profissionais com domínio especializado de conhecimento, sobretudo no que tange à preocupação com o armazenamento, recuperação e preservação da informação na internet, como apresentado por Sayão (2008):

A nova configuração dos sistemas de publicação de informações acadêmicas demanda responsabilidades em muitos níveis. Porém, ao tempo em que a geração e o uso da informação digital se aceleram, a responsabilidade de preservação dos estoques informacionais em formato digital é bastante difusa e as partes responsáveis - pesquisadores, gestores, bibliotecas e editores - têm sido lentas em identificar e investir na infraestrutura imprescindível para assegurar que os registros publicados [...] permaneçam íntegros ao longo do tempo [...] (Sayão, 2008, p. 171).

Ferreira e Targino (2005, p. 24) acreditam que as versões eletrônicas dos periódicos precisam prezar pela qualidade, o que demanda a atuação de profissionais com múltiplos domínios de conhecimento. Desse modo, é necessário estimular a conscientização de que a produção científica é, essencialmente, uma produção intelectual e, por conseguinte, “[...] a elaboração e o uso de periódicos científicos constituem 'espelho' da ciência e da comunidade de cientistas de um país e de uma disciplina, o que, em última instância, significa avaliar o processo desenvolvimentista das nações".

Com efeito, a observância quanto à qualidade da publicação veiculada nos periódicos considera os seguintes aspectos: 1 - qualidade do corpo editorial e integridade do processo de avaliação dos artigos; 2 - adoção de padronização aceita internacionalmente, além da manutenção de periodicidade regular, condição essencial à indexação em fontes internacionais; 3 - utilização de processos gráficos modernos para apresentação correta, rápida e eficaz; e 4 - eficiente relacionamento entre editores e leitores, para que o título mantenha prestígio junto à comunidade (Barbalho, 2005, p. 134). 
Dentre os quatro aspectos mencionados por Barbalho (2005), Ferreira e Targino (2008) evidenciam a participação dos bibliotecários, sobremaneira, na adoção da padronização, na utilização de recursos gráficos e no efetivo relacionamento com os envolvidos com a publicação de um manuscrito. $\mathrm{Na}$ visão dessas autoras, a digitalização e as redes globais têm transformado de tal modo as características das publicações científicas, que profunda mudança paradigmática está em curso. "[...] Essa mudança altera o papel dos vários atores envolvidos no processo de publicação, afetando até mesmo suas relações de poder e, em consequência, criando uma revolução política, no sentido mais fiel da palavra" (Ferreira \& Targino, 2008, p. 1).

A questão da forma de apresentação dos artigos é outro aspecto muito abordado na literatura acerca das contribuições do bibliotecário ao atuar na editoração eletrônica de periódicos. A respeito desse fazer,

não se espera de um pesquisador ou cientista que produza textos perfeitos, mas, no mínimo, que dê importância à redação, em respeito ao leitor. Ao construir textos claros, corretos, objetivos, concisos e precisos, favorece a disseminação de seus trabalhos. O texto bem escrito, refletindo pesquisa de qualidade reconhecida, mantém maior chance de ser publicado e poupa ao público-leitor a execução de complexos exercícios mentais para compreendê-lo (Barradas \& Targino, 2008, p. 37).

As autoras supracitadas mencionam que um texto científico precisa apresentar as seguintes características: clareza, precisão, simplicidade, objetividade, concisão/coesão/brevidade, harmonia, vigor, elevação da linguagem, fidelidade às fontes e correção.

Com esse propósito, entram em cena as práticas de normalização realizada por bibliotecários. Logo, Ferreira (2005, p. 270) afirma que essa atividade em periódicos científicos precisa ser uma atividade contínua e reguladora, pois "[...] unifica formas e procedimentos, além de favorecer e facilitar a transferência da informação".

\section{Metodologia}

No intuito de se atingir o propósito principal deste estudo, qual seja "apresentar atividades desempenhadas por bibliotecário no processo de editoração de periódicos eletrônicos, de modo a confirmar as possibilidades empreendedoras advindas desse contexto de trabalho", metodologicamente, adotaram-se duas modalidades de pesquisa, que são: pesquisa bibliográfica e relato de experiência, ambas caracterizadas como estudos de natureza qualitativa, uma vez que se adentraram a discussões teóricas e constatações advindas de uma atuação prática.

A pesquisa bibliográfica alicerçou-se na análise a diferentes fontes de informação publicadas, como livros e artigos científicos, tendo como conteúdo investigado nessas fontes, a atuação empreendedora do bibliotecário na editoração de periódicos eletrônicos. A seleção dessas fontes foi conduzida pela consulta à base de dados do Google Acadêmico e da Base de Dados em Ciência da Informação (BRAPCI). Assim, a maioria 
dos trabalhos escolhidos foi artigos científicos, com baixa predominância de publicações em formato de livros, conforme descrito na lista de referências, ao final deste texto.

Por sua vez, a experiência aqui narrada diz respeito à inserção de um bibliotecário junto a uma equipe editorial de um periódico eletrônico de acesso aberto. Importante frisar que, mesmo que essa atuação tenha sido de forma voluntária (como acontece com todos os atores que estão envolvidos com a produção científica de periódicos que aderem ao movimento do acesso livre ao conhecimento), as práticas de trabalho, como também, as observações realizadas pelo profissional, foram suficientes para fundamentar e evidenciar práticas empreendedoras a serem desenvolvidas por bibliotecários nesse segmento de trabalho direcionado à editoração periódica.

\section{Apresentação e análise de resultados}

O periodismo pode ser considerado como um dos grandes marcos históricos na história dos registros gráficos do conhecimento, como também provocou inúmeras transformações no mercado editorial e na forma com que as pessoas buscam e acessam informação, sobretudo pelo fato dos periódicos manifestarem-se como publicações de natureza contínua. No âmago científico, os periódicos revolucionaram os fazeres científicos, provocando rapidez na forma de se socializar os achados de pesquisa (Rodrigues \& Marinho, 2009).

O uso da editoração eletrônica facilitou ainda mais as relações firmadas entre cientistas, de modo que esse formato de periódico tem se evidenciado, a cada dia, como a principal fonte de informação para a atualidade (Oliveira, 2008). As peculiaridades desses registros - tais como sua continuidade, aliado ao crescimento do número de periódicos nas diversas áreas do conhecimento - demandaram o uso de técnicas e métodos específicos para garantir o tratamento, gestão, armazenamento e uso dessas publicações na sociedade (Fachin \& Hillesheim, 2006).

As autoras supracitadas mencionam que as bibliotecas são consideradas como espaços ou unidades de informação mais apropriadas para armazenar e tratar as coleções de periódicos, e também destacam o papel dos bibliotecários, considerados como profissionais da informação especializados para tratar as coleções periódicas.

Todavia, a prática bibliotecária junto aos periódicos não deve se limitar, tão somente, às atividades de organização dessas publicações. Além disso, os bibliotecários podem atuar, também, no mercado editorial dos periódicos, como relatado no estudo de Santana (2016, p. 13-14), para quem, a contribuição desse profissional, no processo de produção editorial de periódicos científicos, permite "[...] tanto a aplicação de conhecimentos específicos da área de Biblioteconomia e Ciência da Informação, bem como de conhecimentos relacionados a outras áreas profissionais [...]", apresentando, portanto, uma maior complexidade e, por conseguinte, 
exigindo do bibliotecário novas competências e habilidades.

No âmbito da editoração eletrônica, ressalta-se que novas potencialidades são oriundas com esse processo, de modo que o bibliotecário tende a atuar na condução das etapas editoriais, por meio de seu conhecimento em organização das informações no ambiente digital, o que demanda, além das técnicas tradicionais de representação, o domínio no uso das ferramentas presentes nas plataformas digitais. Assim, “[...] pensar em editoração eletrônica é pensar num novo nicho de atuação profissional, abrindo ainda mais esse leque de oportunidades" (Maiome \& Tálamo, 2008, p. 318).

Em linhas gerais, essas autoras identificaram três importantes atribuições demandadas aos bibliotecários quanto ao uso das plataformas digitais que gerenciam os periódicos, que são: 1 - a normalização de documentos; 2 - a análise de trabalhos técnico-científicos e, 3 - a organização e gerenciamento de bases de dado virtuais.

Estudo recente desenvolvido por Santana (2016, p. 22) evidenciou que os fazeres bibliotecários em periódicos eletrônicos, embora ainda pouco reconhecido, se concretizados, tendem a se tornar um potencial de atuação desse profissional, o que pode consolidar a prestação de serviços bibliotecários na gestão das plataformas, bases de dado e de todo o processo e fluxo editorial demandado desse novo contexto. Assim,

é importante salientar que mudanças hoje observadas no âmbito das equipes editoriais de periódicos científicos se deram muito em função das transformações tecnológicas e da importância que os periódicos assumiram no processo de comunicação e divulgação científica, que exigem conhecimentos, habilidades e competências cada vez mais específicos, dada as demandas que se impõem. Essas mesmas mudanças possibilitam ao bibliotecário desempenhar papéis estratégicos, bem como assumir funções com níveis maiores de complexidade e responsabilidade nas equipes editoriais (Santana, 2016, p. 22, grifo nosso).

Assim, os bibliotecários, em conjunto com profissionais ligados a áreas de Tecnologia, Design Gráfico, Comunicação, Marketing, dentre outras, encontram oportunidades de exercerem atividades profissionais na editoração eletrônica, uma vez que os sistemas e softwares utilizados nesse processo precisam ser constantemente monitorados, permitindo que sejam exploradas as possibilidades que esses recursos podem oferecer (Coutinho \& Buse, 2014, Santos, 2016).

As equipes que atuam na gestão dos periódicos, normalmente, estão envolvidas em diversas atividades, contempladas nas mais diferenciadas etapas do extenso fluxo editorial, o que evidencia a presença de práticas profissionais inerentes à gestão de cunho científico (a análise do conteúdo, contemplando a avaliação do que será publicado), quando à gestão de cunho administrativo, ou seja, processos de trabalho que viabilizam o funcionamento do software utilizado pelo periódico, quanto a outras questões que possam afetar a disponibilização do que é publicado nas edições (Guimarães \& Diniz, 2014). 
Em linhas gerais, na gestão científica, segundo os autores supracitados, manifesta-se a presença dos editores, avaliadores, corpo editorial científico e o comitê de política editorial. Por sua vez, a gestão administrativa é formada por produtores editoriais e gráficos, gestores administrativos e financeiros, profissionais da comunicação e marketing.

De qualquer forma, para que esse conjunto de atividades diferenciadas possa ser bem conduzido e o fluxo da comunicação científica (processo primordial que permeia o contexto de qualquer periódico) se realize de forma efetiva, "[...] o periódico precisa de uma equipe interna e/ou externa (terceirizada) consistente e comprometida, além de infraestrutura física e tecnológica adequada" (Guimarães \& Diniz, 2014, p. 458).

Nesse contexto, evidenciam-se as possibilidades empreendedoras que podem surgir a partir das necessidades que se manifestam com a implantação e aceitação, cada dia mais frequente, dos periódicos em formato eletrônico. Desse modo, os bibliotecários, como outros profissionais da informação, por possuírem habilidades e competências específicas para lidar com o tratamento, organização e disseminação de objetos informacionais, como os periódicos, têm um campo de trabalho promissor, sobretudo no que se refere à consultoria ou prestação de serviços informacionais para os periódicos científicos (Santana, 2016).

Normalmente, as complexidades demandadas nos processos de trabalho com os periódicos eletrônicos requerem a formação de equipes multiprofissionais, as quais os profissionais atuantes podem ser caracterizados como empresários da informação, como relatado na obra de Le Coadic (1996). Nas palavras desse autor, esse grupo é constituído por profissionais da informação "[...] que criam empresas de fabricação e venda de produtos ou serviços de informação, o produto da informação pode ser um banco de informações especializadas, um programa de computador, publicações, índices, catálogos etc.” (Le Coadic, 2004, p. 108).

Por fim, a editoração de periódicos, sobretudo a eletrônica, manifesta-se como uma oportunidade viável para oportunizar práticas empreendedoras por parte dos bibliotecários e demais profissionais que lidam com a informação, de modo que, novos campos de trabalho possam ser formados, desencadeando ao bibliotecário, um perfil multidisciplinar, com intervenções direcionadas à consultoria prestada no amplo mercado da informação (Fernandes \& Pires, 2012, Coutinho \& Buse, 2014).

Após apresentação e contextualização dos dados coletados na literatura, constatam-se as oportunidades de trabalho para o bibliotecário, surgidas com a editoração eletrônica de periódicos científicos. Sendo assim, apresenta-se, a seguir, discussão das observações e vivências experienciadas a partir da participação de um bibliotecário junto à equipe editorial de um periódico científico eletrônico. 


\section{Discussão da experiência prática}

Para fins de apresentação das atividades realizadas na experiência ora relatada, importante mencionar o contexto de atuação profissional, qual seja, um periódico científico de acesso aberto, vinculado a um Programa de PósGraduação em Educação de uma universidade pública, cujo periódico está gerenciado pelo software Open Journal Systems (OJS) ${ }^{2}$.

O periódico científico em que o bibliotecário prestou atividades de assessoria e consultoria tem como principal objetivo promover a divulgação da produção acadêmica sobre a educação nas suas múltiplas relações e contribuir para debates de questões relacionadas com o contexto educacional em suas diferentes dimensões.

Observa-se, portanto, que, embora pertença à área da Educação, o periódico apresenta-se com um alcance interdisciplinar, envolvendo questões de pesquisa das mais variadas e levantadas por diferentes campos do conhecimento. O periódico publica diferentes modalidades de fontes de informação, tais como: artigos, resenhas e entrevistas.

O periódico está estruturado por diferentes comissões, compostas por profissionais de diversos campos, com predominância do campo educacional. De um modo geral, nota-se a presença de duas grandes comissões que são: comissão científica e comissão editorial. A primeira responsabiliza-se pela avaliação dos trabalhos submetidos, enquanto a segunda comissão preocupa-se com questões de cunho administrativo e, também, em alguns casos, científico. A comissão editorial se divide em três grupos: editores chefes, comitê editorial e comitê assessor. Ressalta-se que o bibliotecário ingressou-se nas três comissões, auxiliando o trabalho das equipes, especificamente no que tange a serviços direcionados à prática de organização de documentos e assessoria no manuseio da plataforma da revista.

A vinculação do bibliotecário à equipe editorial dessa revista oficializou-se no ano de 2014, permanecendo em vigor até o atual momento. A princípio, o profissional teve que se especializar acerca do sistema utilizado pela revista, uma vez que as atividades de organização e diagramação das novas edições são realizadas, exclusivamente, pela plataforma do SEER, conforme demonstrado na figura 1.

\footnotetext{
${ }^{2}$ Constitui um software desenvolvido pela Universidade BritishColumbia, por meio do Public Knowledge Project (PKP). No Brasil, foi traduzido e customizado pelo Instituto Brasileiro de Informação em Ciência e Tecnologia (IBICT) e recebe o nome de Sistema Eletrônico de Editoração de Revistas (SEER). Trata-se de um software desenvolvido para a construção e gestão de publicações periódicas eletrônicas (Santos, 2016).
} 
Figura 1 - Interface do SEER no âmago do periódico gerenciado pelo bibliotecário

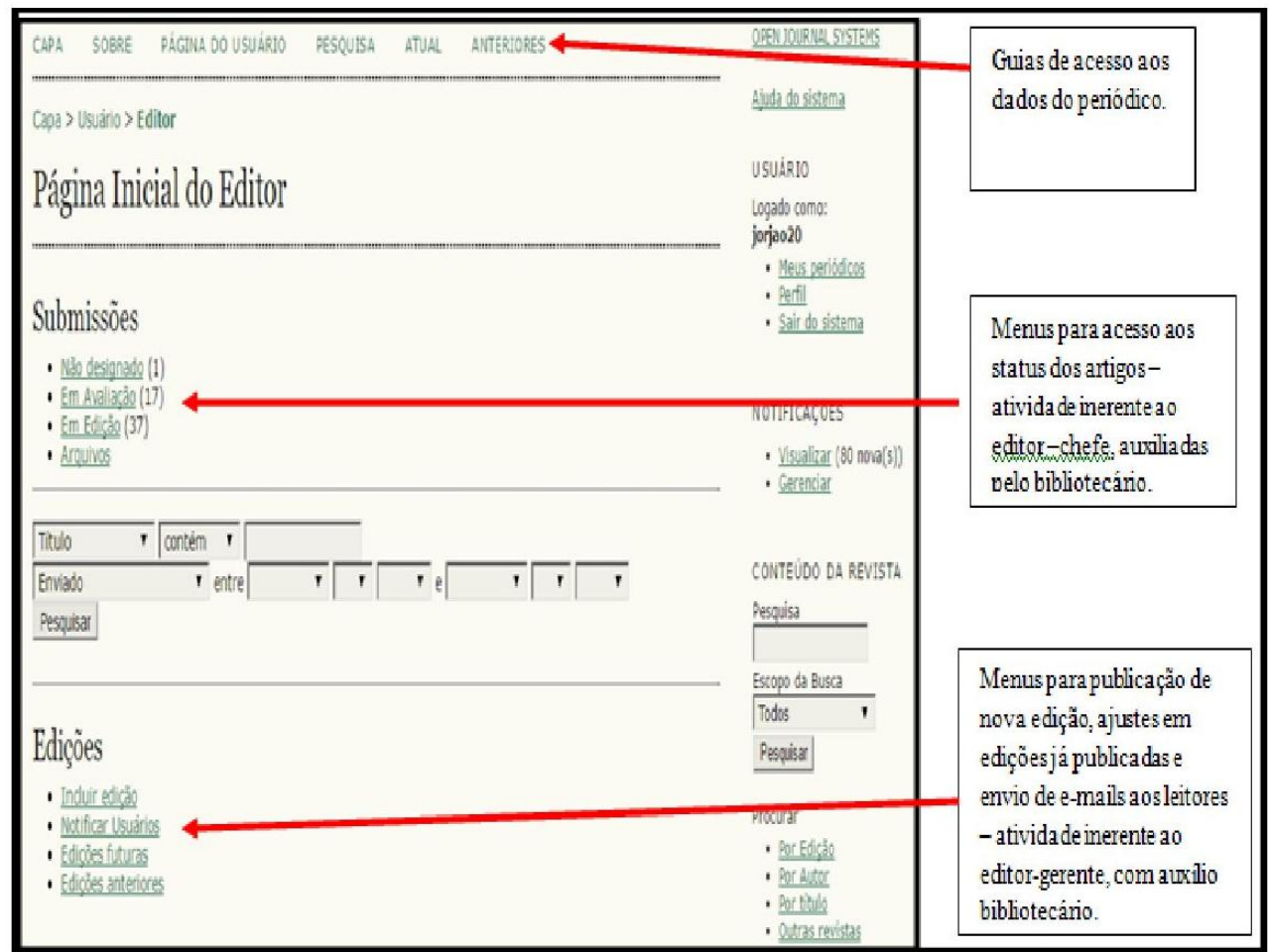

Fonte: dados da pesquisa (2018).

Como demonstrado na figura 1 , o bibliotecário foi inserido na equipe editorial da revista, de modo a exercer diversas funções, principalmente no que se refere a auxiliar o papel do editor chefe (gestão administrativa) e o papel do editor gerente (gestão científica).

Em linhas gerais, essas duas funções são sustentadas por inúmeras atividades, concretizando-se após o processo de avaliação dos manuscritos enviados à revista. Os manuscritos aprovados pelo comitê avaliador são encaminhados via plataforma SEER ao editor gerente, sendo que esse encaminha ao bibliotecário para que seja realizada as atividades de revisão textual e normalização dos artigos. Após esse processo, manifestam-se as atividades de tratamento, organização e disponibilização dos documentos (tais como gestão dos metadados), e, logo em seguida, realiza-se o processo de diagramação da estrutura que comporá a nova edição. Por fim, a nova edição da revista é publicada.

Nesse contexto, o bibliotecário atua junto à equipe do comitê editorial e, também, no assessor. Portanto, ao receber os manuscritos, devidamente aprovados, o comitê editorial e o assessor atribuem ao bibliotecário as seguintes funções, executadas de forma sequencial:

$\checkmark 1$ - revisar os trabalhos aprovados, zelando pelo cumprimento das especificações técnicas e formatações do texto, sobretudo no que diz respeito à revisão gramatical, morfológica, ortográfica e sintática;

$\checkmark 2$ - adequar os trabalhos, conforme as normas de formatação estabelecidas pela revista, a qual adota as normas bibliográficas instituídas pela Associação Brasileira de Normas Técnicas (ABNT); 
$\checkmark 3$ - elaborar a arte gráfica da publicação on-line da revista (diagramação), agrupando em um único documento, os trabalhos aprovados e demais elementos a compor a nova edição;

$\checkmark 4$ - publicação de uma nova edição da revista na plataforma SEER (gerenciamento da plataforma eletrônica), enviando comunicado aos usuários cadastrados na plataforma (leitores, autores, colaboradores etc.).

A figura 2 demonstra as principais atividades desenvolvidas pelo bibliotecário, sendo que tais atividades são desenroladas de forma processual, ocasionando - assim como acontece em outras fases da editoração em que o bibliotecário não participa - um fluxo interativo, relacional e contínuo.

Figura 2 - Fluxo das principais atividades realizadas pelo bibliotecário

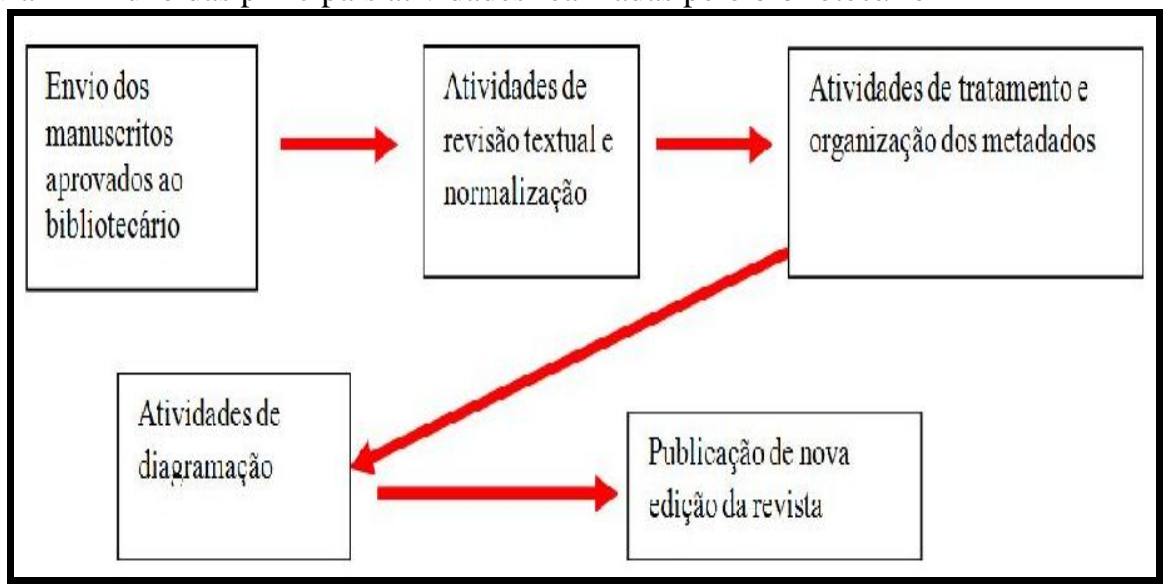

Fonte: dados da pesquisa (2018).

Por meio das análises às figuras supracitadas, evidencia-se que o bibliotecário atua de forma interativa e multiprofissional com os demais membros da equipe editorial da revista, como também em parceria com outros profissionais ligados às áreas de Tecnologia, Design Gráfico, dentre outros.

Enfatiza-se, outrossim, que o bibliotecário exerce, a priori, os papéis de assessor, junto ao editor da revista, cadastrando usuários, delimitando papéis aos membros da equipe, melhorando a interface da revista, inserindo e/ou atualizando as informações disponibilizadas no site da revista, conforme figura 1. Além disso, são delegadas a esse profissional funções exclusivas, de acordo com suas habilidades na organização da informação. Portanto, essas atividades constituem as etapas finais do fluxo editorial, de modo que, em linhas gerais, elas visam melhorar a qualidade da escrita dos artigos, como também, efetivar o tratamento documentário das publicações e, por fim, elaborar a estrutura final da nova edição, a qual é, logo em seguida, disponibilizada ao público (publicada) (figura 2).

Especificamente, no que tange às atividades de revisão dos textos, percebese que ela requer um conhecimento especializado, considerando as regras instituídas pela Norma Culta da Língua Portuguesa. Para realização desse trabalho, o manuscrito enviado ao profissional é analisado, conforme os 
próprios recursos de revisão disponibilizados no editor de texto Word. Havendo muitas correções a serem feitas, o profissional insere os comentários no próprio documento, retornando o arquivo aos editoreschefes para que realizem os ajustes, comunicando, se necessário, os autores. Em todo o trabalho de revisão, é considerada a adequação às normas gramaticais, no que tange à ortografia, pontuação, acentuação, sintática e coerência.

Quanto às atividades de normalização, ela contempla o uso ou aplicação das normas bibliográficas em trabalhos acadêmico-científicos, cuja finalidade dessa intervenção é, primordialmente, permitir que os trabalhos tornem-se padronizados, com formatos adequados para uma leitura mais agradável. Dessa forma, a revista, ao publicar trabalhos padronizados, proporciona, além do entendimento, mais comodidade a seus leitores. Semelhante à revisão textual, a normalização é executada com o uso dos recursos de revisão ofertados pelo Word. Os ajustes são realizados no próprio documento submetido pelo autor.

No que se refere às atividades de tratamento e organização dos metadados, é realizada análise aos dados que representam a forma e o conteúdo dos documentos submetidos, com o intuito de proporcionar a padronização dos registros, como também contribuir para a recuperação dos documentos, quando em um processo de busca e recuperação pelos usuários, em bases de dado ou outros ambientes que proporcionem esse fim. Assim, o profissional revisa o cadastro realizado pelos próprios autores, quando o manuscrito foi submetido, ajustando alguns metadados, como: nome dos autores, vinculação institucional, instituições de fomento à pesquisa, palavras-chave dos manuscritos, dentre outros. Para que possíveis ajustes sejam realizados nesses dados, o profissional envia contato aos autores, solicitando a autorização para proceder a essas mudanças.

Por fim, quanto às atividades de diagramação e gerenciamento da plataforma eletrônica, ela se realiza em parceria com os editores-chefes e corresponde à inserção dos trabalhos revisados/normalizados na plataforma SEER. Antes, porém, executam-se atividades de compilação de todos os manuscritos, como também outros elementos que formarão a nova edição, como editorial, expediente e sumário. Portanto, esses elementos são fundidos em um único documento, com páginas numeradas sequencialmente e sendo inserido, no rodapé de todas as páginas do documento, a legenda bibliográfica da nova edição.

Após essa compilação, o arquivo é transformado em PDF e inserido na plataforma SEER, sendo disponibilizado no ambiente web para acesso ao público. A fim de finalizar o processo editorial referente à publicação da nova edição, é realizado o envio de e-mail, a todos os usuários cadastrados na revista, de modo a garantir maior visibilidade no acesso e uso dos trabalhos publicados.

Com efeito, o exercício dessas atividades, em linhas gerais, requer a capacitação do profissional, por meio de cursos, treinamentos, dentre outras 
estratégias que podem ser adotadas no percurso da formação continuada. Em conjunto, o trabalho realizado pelo bibliotecário, no âmbito da editoração, tem como principal finalidade viabilizar uma leitura mais produtiva e agradável do documento, conforme discorrido no estudo de Souza (2017).

Assim, o bibliotecário, ao atuar no contexto da editoração, seu trabalho não se restringe apenas aos serviços de normalização. Há várias atividades e funções desempenhadas por esse profissional que advêm da formação acadêmica, por um lado, e que, por outro, é desenvolvida a partir da capacitação ou aprimoramento profissional, o que enfatiza a necessidade do investimento na formação continuada, de modo a reforçar o caráter multidisciplinar da profissão, ampliando a área de atuação bibliotecária. Devido às habilidades e competências que possui, o bibliotecário pode ser inserido na equipe editorial, para somar, junto ao editor e demais membros das equipes, visando uma melhor qualidade dos materiais publicados (Souza, 2017).

Essas atividades, de um modo geral, indicam a ampliação das práticas bibliotecárias, confirmando a atuação do bibliotecário no âmbito da editoração de periódicos científicos eletrônicos. Tais contribuições ao fluxo do processo editorial, por serem realizadas em periódico de acesso livre, desencadeou a atuação voluntária do profissional; no entanto, essas mesmas atividades podem ser realizadas no âmago dos periódicos de acesso restrito.

Além disso, essas atividades, dependendo da gestão do periódico, podem ser contratadas por profissionais externos, o que viabiliza possibilidades empreendedoras para aqueles que desejam inserir-se na prestação de serviços, ou seja, elas representam um segmento da consultoria informacional.

Ademais, por meio da observação ao trabalho do bibliotecário neste periódico, evidenciam-se outras atividades mais complexas, que, na maioria das vezes, não podem ser realizadas pela equipe editorial, o que demanda a contratação de serviços especializados. Assim, é possível evidenciar algumas intervenções de consultores nos periódicos, tais como: o monitoramento, atualização e manutenção do SEER; a construção de bases de dados para incorporar a memória publicada no periódico; a elaboração de bancos de dado com vocabulários controlados, tendo em vista facilitar o processo de busca e recuperação da informação; a migração ou incorporação entre bases de dado, visando melhorias no armazenamento e recuperação, dentre outras atividades.

Em suma, a editoração periódica nos ambientes digitais é um episódio da história das ciências e da humanidade que reconfigurou os meios de comunicação das pesquisas, logo, por estar em processo de consolidação, desafios surgem com frequência, fato esse que demonstra a origem de novos campos de atuação por parte de profissionais de inúmeras áreas do conhecimento, sobretudo dos profissionais ligados à organização da informação, como os bibliotecários. 


\section{Considerações finais}

Os procedimentos metodológicos utilizados neste artigo demonstraram a atuação do bibliotecário na editoração de periódicos eletrônicos. Constatouse que esse profissional auxilia nas atividades de gestão do periódico, melhorando a interface da revista e atribuindo papéis aos membros da equipe, como também desempenha, de forma exclusiva, as atividades de revisão textual e normalização; tratamento e organização de metadados; diagramação; e, por fim, publicação de nova edição.

Além dessas atividades, outras mais complexas se fazem necessárias, como a manutenção do sistema de gerenciamento e elaboração de estratégias que melhorem o armazenamento da produção científica e acarrete melhorias no sistema de recuperação da informação.

Em conjunto, essas atividades manifestam-se como possibilidades empreendedoras para os bibliotecários que podem atuar na prestação de serviços, tendo em vista resolver os desafios que se colocam no processo de editoração eletrônica dos periódicos. Que essas evidências despertem a formação de profissionais especializados, de modo que esse segmento de mercado seja ocupado pelo bibliotecário, oportunizando ainda mais o mercado de trabalho para esse profissional.

Logo, espera-se que os resultados aqui evidenciados possam despertar atitudes empreendedoras nos bibliotecários, como também o reconhecimento e valorização da prática profissional em diversas instâncias da sociedade. Além disso, faz-se necessário despertar a necessidade de capacitação do bibliotecário, de modo que possa ocupar esses segmentos de atuação profissional, conforme demandas da sociedade.

Portanto, sugerem-se novos estudos sobre este assunto, tendo em vista sua amplitude em face dos diferentes ramos de atuação bibliotecária, considerando a dinamicidade e instabilidade das necessidades sociais. Especificamente, quanto ao campo da editoração periódica eletrônica, é preciso aprofundar as reflexões, no intuito de identificar, fortalecer e/ou disseminar as ações participativas do bibliotecário nesse processo. Trata-se, por fim, de um terreno fértil para pesquisa e que, certamente, representa o iniciar de uma longa, necessária e complexa discussão.

\section{Referências}

BARBALHO, C. R. (2005). Periódico científico: parâmetros para avaliação de qualidade. In Sueli Mara Soares Pinto Ferreira \& Maria das Graças Targino (Orgs.), Preparação de revistas científicas: teoria e prática. São Paulo: Reichmann \& Autores, pp. 123- 158. 
BARRADAS, M. M.; TARGINO, M. das G. (2008). Redação de artigo técnico-científico: a pesquisa transformada em texto. In Sueli Mara Soares Pinto Ferreira \& Maria das Graças Targino (Orgs.), Mais sobre revistas científicas: em foco a gestão. São Paulo: Editora Senac, pp. 17-40.

BURKE, P. (2003). Uma história social do conhecimento: de Gutenberg a Diderot. Rio de Janeiro: J. Zahar.

COUTINHO, A.J.; BUSE, J. (2014). A criação de periódicos eletrônicos na disciplina de editoração como práticas de ensino. Múltiplos Olhares em Ciência da Informação, 4 (2), pp. 1-18. Recuperado de portaldeperiodicos.eci.ufmg.br/index.php/moci/article/download/2549/1620

FACHIN, G.R.; HILLESHEIM, A.I.. (2006). Periódico científico: padronização e organização. Florianópolis: Ed. da UFSC.

FERNANDES, E.N.; PIRES, E.A. (2012). O bibliotecário consultor: perfil profissional. Biblionline, 8 (2), pp. 62-73. Recuperado de http://periodicos.ufpb.br/index.php/biblio/article/view/12285/8638

FERREIRA, S.M.; TARGINO, M. das G. (Orgs.). (2005). Preparação de revistas científicas: teoria e prática. São Paulo: Reichmann \& Autores.

FERREIRA, S.M.; TARGINO, M. das G. (Orgs.). (2008). Mais sobre revistas científicas: em foco a gestão. São Paulo: Editora Senac.

FERREIRA, S.M. (2005). Critérios de qualidade para as revistas científicas em comunicação. In Sueli Mara Soares Pinto Ferreira \& Maria das Graças Targino (Orgs.). Preparação de revistas científicas: teoria e prática. São Paulo: Reichmann \& Autores, pp. 269-294.

GUIMARÃES, L.V.; DINIZ, E. Gestão de periódicos científicos: estudo de casos em revistas da área de Administração. (2014). Revista de Administração, 49 (3), pp. 449-461. Recuperado de 200.232.30.99/download.asp?file=RAUSP_v49n3_449-461.pdf

KNAPP, W. (1992). O que é editora. 2. ed. São Paulo: Brasiliense.

LE COADIC, Y.-F.. (2004). A ciência da informação. 2. ed. Brasília, DF: Briquet de Lemos.

MAIOME, G.; TÁLAMO, M. de F.. (2008). Atuação do bibliotecário no processo de editoração de periódicos científicos. Revista $A C B$ :

Biblioteconomia em Santa Catarina, 13 (2), pp. 301-321. Recuperado de https://revista.acbsc.org.br/racb/article/view/522/659

MATHEWS, B. (2007). O bibliotecário como empreendedor: um projeto para transformar o nosso futuro. ExtraLibris.

MCGARRY, K. (1999). O contexto dinâmico da informação: uma análise 
introdutória. 2. ed. Brasília: Briquet de Lemos.

OLIVEIRA, É. B. (2008). Periódicos científicos eletrônicos: definições e histórico. Informação \& Sociedade: Estudos, 18 (2), pp. 69-77. Recuperado de http://www.ies.ufpb.br/ojs/index.php/ies/article/view/1701/2111

RODRIGUES, J.; MARINHO, S.M.. (2009). A trajetória do periódico científico na Fundação Oswaldo Cruz: perspectivas da Biblioteca de Ciências Biomédicas. História, Ciências, Saúde, 16 (2), pp. 523-532. Recuperado de http://www.scielo.br/pdf/hcsm/v16n2/16.pdf

SANTA ANNA, J.; PEREIRA, G. (2014). Ampliando o campo de atuação bibliotecária: o bibliotecário como consultor informacional. Revista ACB, Florianópolis, 19 (2), pp. 163-173.

SANTA ANNA, J.; SILVA, E.B.; COSTA, M.E.. (2018).

Empreendedorismo bibliotecário na sociedade da informação: outros caminhos e possibilidades. Belo Horizonte: ABMG.

SANTANA, S. A. (2016). O bibliotecário e a editoração de periódicos científicos: fazeres e competências. 80f. Trabalho de Conclusão de Curso (Monografia) - Departamento de Ciência da Informação, Universidade de São Paulo, USP, São Paulo.

SANTOS, G. C. ( 2016). Processo de criação de um periódico científico. Recuperado de http://www.sbu.unicamp.br/seer/ojs/index.php/ppec/article/view/6975

SAYÃO, L. F. (2008). Preservação de revistas eletrônicas. In Sueli Mara Soares Pinto Ferreira \& Maria das Graças Targino (Orgs.). Mais sobre revistas científicas: em foco a gestão. São Paulo: Editora Senac, pp. 167210.

SOUZA, G. S. de. (2017). Editoração de livros: a parceria entre bibliotecário e editor. $34 \mathrm{f}$. Trabalho de Conclusão de Curso (Graduação) Instituto de Ciências Sociais Aplicadas, Universidade Federal do Pará, Belém.

VALENTIM, M. L. (2000). Atuação e perspectivas profissionais do profissional da informação. In Marta Lígia Pomim Valentim (Org.). $O$ profissional da informação: formação, perfil e atuação profissional. São Paulo: Polis, pp. 135-152. 